\title{
Walter Benjamin: do estado de excecão à terra sem mal
}

\section{Resumo}

Este ensaio desenvolve a concepção benjaminiana da modernidade como retorno do destino antigo e domínio do acaso. Temporalidade barroca, ela é a hora das aparições porque os espíritos são fantasmas sem história cujo tempo é espectral, a meio caminho entre o real e o irreal. Do ponto de vista político, esse tempo é o da indeterminação entre democracia e absolutismo, entre estado de direito e estado de exceção. O verdadeiro estado de exceção é a utopia da sociedade sem classes, sem poderes coercitivos: a Terra sem Mal.

\section{Abstract}

This essay develops Benjamin's conception of modernity as the return to the antique destiny and domination of chance. Baroque temporality - it is the hour of apparitions, because the spirits are ghosts with no history to whom time is spectral, in the middle of the way between what is real and what is unreal. From a political point of view, this is the time of the indetermination between democracy and absolutism, between the state of Right and the state of exception. The real state of exception is the utopia of a society without classes, without coercive power: the land of no Evil.

Tragédia e tristeza constituem, no Drama Barroco Alemão, dois conceitos fundantes, aptos a proceder à hermenêutica do presente. Se o fenômeno trágico prende-se à Grécia antiga e à fatalidade, à tragédia barroca corresponde uma filosofia da história na qual encontram-se tensionados natureza e história, imanência e transcendência,chronos e kairós. Da tragédia antiga depreende-se o destino, força exterior e implacável, que transita entre os excessos heróicos e a ordem divina. A morte do herói trágico é teleológica, inteiramente vivida por uma necessidade interna que lhe é própria, assim encontrando-se consigo mesmo, o que confere identidade heróica ao herói. Diferenciando-se da tragédia grega, o Trauerspiel é a apresentação filosófica e histórica do presente que se tornou profano. Razão pela qual Benjamin anota: "não existe escatologia barroca".

Porque a cosmotragédia grega desaparece com o protestantismo, Benjamin lembra que os autores das tragédias barrocas alemãs eram luteranos. Com isto, à teoria da história Benjamin associa uma filosofia da religião, uma 
vez que não é estranha ao DBA a problemática jansenista do Deus Absconso, inteiramente desconhecido ao homem que ignora os desígnios da Providência. Nesta perspectiva, cada indivíduo encontra-se observado simultaneamente por um Deus escondido e confrontado ao destino que se impõe como necessidade histórica No afastamento do divino, a Terra perde o eixo do Sol e se encontra à deriva no Universo. ${ }^{1} \mathrm{O}$ sentimento de tristeza e desamparo de uma Terra sem Céu faz do planeta, do ponto de vista da " história do Ser", um astro errante. $^{2}$ Aqui manifestam-se os perigos detectados por Pascal na nova física atéia que mergulhava o filósofo no pavor dos espaços infinitos e o "silêncio eterno." O homem, sem vínculos com a transcendência e abandonado ao acaso, só reconhece Deus quando ele irrompe em sua vida produzindo milagres ou pela ação da graça. A Reforma protestante e a tragédia barroca "organizam o pessimismo", destruindo o ethos histórico: "lá onde a Idade Média apresenta a caducidade do mundo e a fugacidade da criatura como estações no caminho da salvação", escreve Benjamin, "o Trauerspiel alemão imerge profundamente na desolação(Trostlosigkeit) da condição terrena. Se conhece alguma redenção, esta se encontra mais nas profundezas da sorte do que na realização de um plano divino"(DB p 82). A época barroca, em que o homem é uma criatura fraca, pecadora e mortal, seculariza conceitos teológicos no Absolutismo político. A escatologia cede o lugar à catástrofe, uma vez que o homem se encontra, neste mundo privado do além, sem qualquer saída do labirinto da história.

Valendo-se da Teologia Política de Carl Schmitt, na qual o deus todopoderoso torna-se legislador onipotente, Benjamin reconhece na jurisdição política moderna "conceitos teológicos secularizados". Estes surgem na tragédia barroca como "estado de exceção", o que leva Benjamin a interrogar o conceito de Soberania:"é soberano",lê-se no $D B A$,"quem decide o estado de exceção", o que significa identificar em que medida o Soberano se vincula à Lei e ao Direito e quando cessa a ação legislativa e opera o arbítrio.Assim,o Soberano, podendo abolir o contrato das promessas e obrigações entre ele mesmo e o povo, não necessita responder ao que pensam seus súditos, pois decretar a exceção resulta de uma decisão(Entscheidung ou Dezision), no instante em que ele decide que a "ordem pública" se encontra ameaçada e o Estado em perigo.Eis por que potencialmente o governante já se encontra na posse de plenos poderes e virtualmente acima da Lei: "aquele que reina",

\footnotetext{
${ }^{1}$ Por isso, não é possível ao barroco deduzir o mundo a partir da lógica, segundo os enunciados de Descartes e Espinosa, como o atesta a Melancolia I de Dürer com os objetos da geometrização do espaço inutilizados por serem insuficientes para combater o sentimento melancólico do mundo.

${ }^{2}$ Cf. Heidegger, "Ultrapassamento da Metafísica", in Ensaios e Conferências, trad.
} 
escreve Benjamin, "já está de antemão designado para investir-se de um poder ditatorial no estado de exceção". No aparelho jurídico do século XVII, o governante por direito divino é o monarca que se identifica com Deus, por definição, "infalível": "a teoria da soberania, na qual o caso particular torna-se exemplar, impõe a realização plena da imagem do soberano no sentido do tirano cuja tarefa é restaurar a ordem recorrendo ao estado de exceção". ${ }^{3}$

Para analisá-lo, Benjamin refere-se ao campo atual que o tornou possível: o fim da experiência, da ação exemplar e do modelo moral, do desejo de autoconhecimento e de aperfeiçoamento de si, com o fracasso do papel filosófico e existencial da cultura, substituído por um mundo anti-genealógico,científico e técnico. Sob o impacto da técnica, a primeira Guerra Mundial transformou a Terra inteira em um permanente campo de batalha e em trincheira. $\mathrm{O}$ conflito químico instaurado, o complexo industrial-militar produziu a economia baseada na guerra, bem como desemprego, hiperinfalação e moedas sem valor, a paisagem foi tomada por arames farpados, o céu tingiu-se com o vermelho dos bombardeios. Quanto ao homem, ele se encontrou "a descoberto em uma paisagem onde mais nada era reconhecível, a não ser as nuvens, e,no meio de tudo isso, em um campo de forças atravessado por tensões e explosões destruidoras, o minúsculo e frágil corpo humano"(Experiência e Pobreza"). De tudo isso resta a ruína que não deixou intacta a noção de cultura.

Com a proclamação da República na Alemanha em 1918, a cultura ${ }^{4}$, que o poder de Estado se esforçou em preservar, seria protocolada em Weimar para onde foi transferida a Capital.Esta cidade foi a tentativa de restaurar a herança cultural de Goethe e Schiller, considerada incólome diante das catástrofes do presente.A Weimar de Goethe é a de sua descoberta das ruínas gregas no sul da Itália e, depois,em Herculano; Bach foi organista em sua catedral.E, em meio a este classicismo oficial e na decepção com respeito às humanidades clássicas, e diante da realidade dos campos de batalha para onde

\footnotetext{
${ }^{3}$ Entre os anos 1914-1918, precisamente em 1916, Benjamin escreve "Trauerspiel e Tragédia", um dos estudos preparatórios ao DBA, redigido este em 1924 e publicado em 1928, "Trauerspiel e Tragédia”em meio à Primeira Guerra, o segundo em plena hiperinflação, a crise social, o terrorismo de esquerda e direita e a ascensão do Nazismo. De 1919 a 1933 a Alemanha viveu em estado de exceção.

${ }^{4}$ Se as ruínas do DBA são a consequiência das guerras de religião, a modernidade assiste àquelas engendradas pelas forças anárquicas da ciência e da técnica a serviço do capital prefigurando a primeira Guerra Mundial antes mesmo de deflagrada. As sobrevivências da Alemanha guilhermina na República de Weimar se fazem presentes no período da história alemã que teve início e terminou com uma Guerra.

${ }^{5}$ Cf. Seligmann-Silva, M., “A (perda da) antigüidade e o nascimento da Modernidade”, inO Local da Diferença:ensaios sobre memória, arte, literatura e tradução,ed. 343,SP, 2005.
} 
a juventude foi enviada a partir de 1914, Benjamin observa a "negligência"e o "desprezo"das tragédias barrocas alemãs.Com efeito,a ausência de estudos nas Universidades e de suas encenações,Benjamin o creditava a um recalque histórico.No Trauerspiel o filósofo encontra "um estilo lingüístico violento à altura da violência dos acontecimentos históricos". (DBA, Brasilense, 1983, p. 77). De onde o sucessor do barroco ser o expressionismo moderno.

A imposição dos valores clássicos nos anos da República de Weimar faz com que Benjamin se desvie do século XX ao século XVII, observando ser o more geometrico o resultado do mundo abandonado de Deus, só restando compreendê-lo por "retas, circunferências e planos". À linha reta da "cadeia de razões" cartesiana ou das demonstrações da Ética espinosana, Benjamin substitui o clinamen do pensamento, pois o racionalismo como doutrina filosófica e o historicismo como filosofia da história são homólogos: à noção de continuidade dedutiva e ordem das razões correspondem as filosofias do progresso e as ruínas que o progresso não vê. Razão pela qual o DBA se inicia pela crítica do conhecimento que, segundo um continuum, faz com que o texto converta-se em doutrina, pois,para Benjamin, a doutrina filosófica propriamente dita funda-se na codificação histórica,não podendo ser evocada more geometrico. $\mathrm{O}$ discurso racionalista resulta de um julgamento no qual as palavras se pretendem signos lingüísticos neutros, representantes da essência das coisas: "dada a equação de uma curva, a todo valor de uma abscissa corresponde,necessariamente, uma ordenada", escreve Descartes na Géometrie. Tanto que Euclides é paradigma do more geometrico: "Euclides, para tirar o globo terrestre de seu lugar e transportá-lo para outra parte", escreve Descartes "só pedia um ponto que fosse fixo e seguro"(D do M). Sua universalidade potencial faz com que suas verdades sejam compreensíveis em qualquer língua, independentemente também de mudanças nos costumes e nas instituições, prescindindo de condições de espaço e tempo ou da aprovação do público . No Tratado Teológico-Político Espinosa o confirma: "Euclides, que só escreveu coisas simplíssimas e assim tanto mais inteligíveis é facilmente compreendido por todos em qualquer língua [...]. Não é preciso senão um conhecimento comum, quase rudimentar[...].E aquele a quem chamo aqui Euclides abrange todos aqueles que escreveram em torno a argumentos que, por sua natureza, são compreensíveis"(TTP,Einaudi, 1972,p 201). Se em Descartes a noção de ordem é necessária e natural do ponto de vista do entendimento, ela é nominalista do ponto de vista das coisas.Assim, o século XVII se vê dilacerado entre o " extremo subjetivismo"-fuga do mundo em direção ao Eu que ficciona um mundo representado pelo Sujeito, e a fuga da Terra em direção ao universo com o desenvolvimento da nova astronomia de Galileu. 
$\mathrm{O}$ sujeito moderno se expandiu à medida do espaço físico ou de sua desmedida, interpretando-o matematicamente como res-extensa, enquanto o espaço psicológico foi metafisicamente tomado como res cogitans. Também para Espinosa a ordem é essencial, dado que a ordem e a conexão das idéias é a mesma que a ordem e a conexão das coisas".Não atendendo a um princípio de razão, no barroco, a ordem das coisas não é a mesma das idéias. Assim, o elemento barroco no pensamento de Descartes é, para Benjamin, o dualismo hiperbólico que leva ao delírio de grandeza, como os "insensatos"(insanis) da primeira Meditação, que asseguram ser reis quando "são muito pobres,que estão vestidos de ouro e púrpura quando estão totalmente nus, ou se imaginam colméias ou ter um corpo de vidro", terem uma " cabeça de argila" ou o corpo ser uma abóbora.Na Recherche de la Vérité, Descartes escreve: "esses melancólicos[...]pensam ser colméias ou ter alguma parte do corpo de tamanho enorme." Neste sentido, o DB considera a " drenagem do sujeito" para o exterior, o esvaziamento do sujeito convertido em puro ato de pensar, com a perda do mundo externo e interno, resultando em delírio,delírio de grandeza, quando o doente de vê " de tamanho gigante." Delírio de orgulho na Idade Média, a loucura é,na modernidade, desvario da razão: os muito pobres " acreditam-se vestidos de ouro e púrpura".Vaso de barro, colméia ou cabeça de argila, o corpo extravagante é oco e vazio, como uma abóbora ressecada e esavziada de sua substância. Um homem cujo corpo é de vidro é um ser desencarnado em uma fantástica sublimação, como o desejo insensato " de ser um corpo de uma matéria tão pouco corruptível,como os diamantes, ou ter asas para voar, como os pássaros."(D do M).

$\mathrm{O}$ recurso cartesiano ao diamante ou ao vidro revela que a matéria translúcida corresponde à lucidez da razão na ordem da extensão, como na $5^{\mathrm{a}}$ parte do D do M: “ essa transmutação de cinzas em vidro é mais admirável do que outra qualquer que ocorra na natureza, por isso tenho particular prazer em descrevê-la". Se o corpo de barro é opaco e oco, o vidro é matéria imaterial que a transparência espiritualiza.O louco é um " inspirado", diz coisas cheias de sabedoria mas não deste mundo. A negação epistemológica do corpo—o corpo é de vidro--resulta no desconhecimento do sujeito com relação a seu próprio corpo e de si mesmo, já que se torna descarando.Benjamin escreve: " a auto-absorção levava facilmente a um abismo sem fundo.É o que nos ensina a teoria da disposição melancólica." ${ }^{7}$ Benjamin reconhece no temperamento atrabiliar o sujeito prisioneiro de suas próprias abstrações, pois o racionalismo filosófico e científico só conhece o princípio de identidade e o de contradição, no mais o mundo é acaso ou necessidade: "Descartes considerava que o real

\footnotetext{
${ }^{6}$ Cf.Descartes, OC, ed A.T.,1996,vol X, p 511.

${ }^{7}$ Cf Benjamin, DB p 165.
} 
era o resultado de uma loteria entre os possíveis e Espinosa que todos os possíveis se realizam efetivamente"( Compagnon, Antoine, La Seconde Mainou le travail de la citation, e3d Seuil,Patis,1979,p. 375).

O triunfo do racionalismo filosófico e científico significou o fim do antropomorfismo no conhecimento da natureza, na exclusão do finalismo,da teologia e a idéia de Deus, e determinou o crescimento desmedido da idéia de natureza na qual se incluiu o homem convertido à condição de sujeito do conhecimento e, ao mesmo tempo, objeto natural. Disso resulta que a lei deve regular a natureza como um rei o faz com seus súditos: "Deus estabeleceu as leis na natureza", escreve Descartes, "assim como um rei estabelece leis em seu reino [e não há] nenhuma em particular que não se possa compreender se nosso espírito se puser a considerá-la,e elas são todas mentibus nostris ingeniae, assim como um rei imprime suas leis no coração de todos os seus súditos se ele possuir esse poder[...],Pode-se dizer que, se Deus estabelecera estas verdades [as da ciência], ele também pode mudá-las, como um rei faz com suas leis"8. A analogia entre natureza e política ,ou natureza e história, revela universos intercambiáveis, pois só o costume (usage) faz história e tanto o costume quanto sua codificação dependem do soberano e são direta competência sua ${ }^{9}$. Neste sentido, Benjamin reúne a crítica ao historicismo do barroco através da empatia.Por detrás do triunfo do historicismo no século XIX oculta-se a realidade de uma radical negação da história em nome de um ideal de conhecimento que encontra seu modelo nas ciências naturais. Os dramas barrocos-cujo cenário é um vale de lágrimas de vastos lamentosforam esquecidos sob o impacto do otimismo histórico em voga a partir do iluminismo; e a modernidade compartilha um mesmo ofuscamento.

Esta naturalização da história é entendida no Drama Barroco Alemão como repetição de um tempo espacializado e mecânico . Nos acontecimentos políticos a destruição é periodicamente renovada, "à semelhança das forças naturais[...]. O Trauerspiel expulsa o acontecimento para uma pré-história construída de certo modo nos moldes da história natural[...]. É Lohenstein quem vai mais longe nessa direção. Nenhum outro poeta usou como ele a técnica de privar de sua força qualquer reflexão ética através de uma linguagem metafórica destinada a equiparar o acontecimento histórico com o natural [...]; toda atitude ou discussão eticamente motivadas são radicalmente banidas" ${ }^{10}$. Deste ponto de vista, o DB, ao estabelecer a transitividade entre as leis da natureza e a política, encontra em Descartes o esvaziamento da

\footnotetext{
${ }^{8}$ Oeuvres Complètes, Adam et Tannery,v. I, p 145, 1964, de agora em diante O .C. , A . T.

${ }^{9}$ Acerca dessa consideração cf. $O$.C. , v. VI,14,p. 61 e v.V p 87.

${ }^{10}$ Origem do Drama Barroco Alemão, São Paulo: Brasiliense,1984, pp112-11.
} 
realidade do agir humano, uma vez que o mundo político se rende à vontade arbitrária do Soberano. A ciência e suas leis não constituem,porém, um centro estável,porque,no barroco,as coisas caem no vazio onde não há sustentação ou orientação. Na mathesis universalis da ciência matemática,,o tempo é contínuo e não-qualitativo É neste tempo "que estão inscritas não somente a vida orgânica dos homens, como as manobras do cortesão e as ações do Príncipe que, segundo o modelo de um Deus que governa intervindo em ocasiões específicas, interfere de forma imediata nos negócios do Estado, a fim de ordenar os dados do processo histórico numa seqüência regular, harmônica e, por assim dizer, espacialmente mensurável. 'O Príncipe desenvolve todas as virtualidades do Estado por uma espécie de criação contínua. O Príncipe é o Deus cartesiano transposto ao mundo político"" ${ }^{11}$ Criador de estabilidade e segurança, o Príncipe e o homem de ciência olham o mundo na articulação funcional de elementos construtivos como um relojoeiro pode ver seus próprios artefatos(Paixões da Alma), como um engenheiro (mécanicien) hidráulico(Dióptrica) pode considerar os jogos ilusionistas dos jardins seiscentistas ou pode se assegurar de que os edifícios sejam construídos sobre a rocha e não sobre a areia( $1^{\text {a }}$ parte do Discurso do Método). A lei aqui desempenha um papel apenas formal, pois o elemento estóico na moral barroca significa vencer a fortuna segundo a perspectiva de "pagar um débito" à natureza e conformar-se a suas leis.Contra a desordem, a "legalidade", diríamos hoje,e não "justiça" ". No barroco, tanto o mundo natural, como o político, desconhecem a utopia. Como escreve Banjamin: "segundo a tese do tempo [do séc. XVII],o espírito se comprova no poder; o espírito é a faculdade de exercer a ditadura" 13 .

No mundo desencantado, sem deuses ou demônios, sem valores transcendentes,sobrevive,clandestinamente,o pensamento "pré-moderno" do passado e do mundo antigo. No DB, Benjamin se refere à determinação absoluta das ações humanas por causas ou forças implacáveis, representadas por abstrações incompreensíveis como as noções de Destino, deuses, Deus, Natureza e, por último, a História,com respeito a que observa: "o espírito de

\footnotetext{
${ }^{11}$ (idem, op. cit. p 119).

${ }^{12}$ Cf. "Lettre Apologétique",in $O$. C.,op. cit,VIII B,p 367).; sobre a permanência da tradição do "estado de exceção"ou do "golpe de Estado", conferir a metáfora cartesiana da "vida dos navegantes", dos perigos de naufrágio--, de que Descartes se vale para ilustrar a existência do Soberano e a magnitude dos riscos que o ameaçam. Sobre a justificação do recurso ao maquiavelismo,cf. op. cit.,v.VIII B, 367.

${ }^{13} O D B$, op. cit.,p 120 . Para uma caracterização mais minuciosa sobre o duplo poder do Rei, cf. Ribeiro,R.J.,in Ao Leitor sem Medo, ed. São Paulo: Brasiliense,1984,pp133 a 136 e nota $n$ 5,pp 168-9.
} 
nosso tempo apropria-se de todas as manifestações de mundos intelectuais passados ou distantes[...]. Como um doente que arde de febre transforma em idéias delirantes todas as palavras que ouve, nosso tempo realiza uma identificação afetiva com o passado[...](e) por substituição, procura colocar-se no lugar do criador, como se este, por ter criado a obra, também fosse seu melhor intérprete". Sem genealogia, o homem é um deus nascido de si mesmo, que preenche o vazio deixado pelo fim do "outro" mundo identificando-se com seus objetos e suas abstrações.Nesse sentido, Benjamin, na Premissa Gnoseológica do DB reavê Bergson e sua crítica ao tempo "sem qualidades"das ciências naturais, já que foi este o filósofo quem, pela primeira vez, tratou esse tempo com a expressão homogêneo(Essais sur les données immédiates de la conscience), o mesmo que Benjamin reconhece na Paris do Segundo Império. Aproximando-se de Bergson, Benjamin não considera o desencantamento do mundo o princípio causador da quantificação do universo e do determinismo natural, mas é da confusão entre o espaço e o tempo, preparada pela tradição ocidental greco-latina e judaico-cristã, que é deduzido o princípio de causalidade, ao transferir o tempo das ciências para as questões metafísicas e suas verdades atemporais.A evolução criadora, ao contrário, diz respeito ao tempo que é arché, origem que não é o pressuposto do tempo, mas simultaneidade de diacronia e sincronia. A este tempo bergsoniano, Benjamin acrescenta a idéia de pré-história ${ }^{14}$ e de pós-história em que o acontecido e o que está por vir, em sua heterogeneidade, ocorrem de maneira simultânea. O que a ciência da história considera separadamente, coincide na imediatez em que a pré-história e a pós-história se manifestam em uma unidade movente.

No horizonte da crítica bergsoniana, Benjamin reflete sobre o século XVII no palco barroco, no espaço teatral de sua espacialização. Se o espaço é um continuum homogêneo e simultâneo, o tempo é um continuum homogêneo e sucessivo. E se o tempo trágico é "temporal" e se dá por saltos, no Trauerspiel " pode-se dizer que a história se desenrola no continuum do espaço quase de maneira coreográfica" ${ }^{15}$, de onde decorrem consequiências éticas: ao homem, embricado no plano do mecanicismo da natureza, só resta executar seu plano. Desaparece, de fato, se não de direito, a experiência da liberdade, pois esse universo, em sua indiferença, contém e explica toda a ordem da natureza e do homem, à revelia de sua vontade ou consciência. Benjamin não critica o racionalismo e o historicismo por seu "relativismo ético" ou sua "ausência de conviç̧ões" com respeito a valores tradicionais, ou pela "ausência de valores humanos" universais, mas pela tendência

\footnotetext{
${ }^{14} \mathrm{O}$ termo utilizado por Benjamin é Vorgeschichte — pré-história, proto-história ou história primeva.

${ }^{15}$ DBA, francês,p. 97),
} 
profundamente germânica e dominante na cultura alemã nos anos da Primeira Guerra Mundial, de fazer do conceito Kultur o porta-voz de seus mais altos valores. A Kultur alemã desqualifica o conceito de Zivilisation, esta francesa, portadora, segundo os alemães, de uma vida superficial e uniformizante que ameaça a Europa.

Na senda de Nietzsche ${ }^{16}$, Benjamin, ao contrário, não aceita a idéia da "profundidade alemã" em oposição à "frivolidade francesa", do Geist oposto à Seele, a contraposição entre as grandes produções do espírito alemão e as convenções e a superficialidade da " alma" francesa. Benjamin encontra em Nietzsche a crítica a este ideário da Alemanha de Weimer, que denuncia o "burguês" francês, pacifista, republicano, apegado às idéias de 1789, opondolhe o Bürger alemão-cosmopolita e adversário da política. Assim, a diferença entre o espírito e a política contém a diferença entre cultura e civilização, entre direito de voto e política, por um lado, arte e literatura, liberdade, de outro. A germanidade é a cultura, o espírito, a liberdade, a arte. Deste ponto de vista, todas as forças que se opuseram à Guerra, reunindo-se contra a Alemanha, o teriam feito em nome da "civilização". De onde a guerra levada a termo por Guilherme II ter sido declarada em defesa do espírito alemão contra a civilização ocidental européia. ${ }^{17}$

Para Benjamin, este era o espírito presente em grande parte da vida intelectual e política alemãs, que compreendia a História como "progresso ininterrupto da cultura", esquecendo os vencidos e falsificando seus combates $^{18}$. A concepção continuísta do tempo na física mecânica é estendida à História, de maneira que o tempo natural toma o lugar do tempo histórico, como o Reich dos Mil Anos de Hitler. Por isso Benjamin critica o more geométrico, nele incluindo as variantes do racionalismo na política. Neste sentido, Guenancia escreve: "o mecanicismo, tal como o concebe Descartes, não é nem contrário nem conforme à liberdade humana, ele lhe é totalmente estranho [...]. O mecanicismo expulsa, pois, o homem do Universo depois de

\footnotetext{
${ }^{16}$ Cf. O Nascimento da Tragéida, e Wille zur Macht, Werke, vol XV, ed Elisabeth FörsterNietzsche,.

${ }^{17}$ Esta visão de mundo permanece na Alemanha pelo menos até a Segunda Guerra Mundial.. Lembre-se que ao tempo de Benjamin ainda não se encontravam disponíveis as obras completas de Nietzsche, tendo o filósofo consultado a edição preparada pela irmã de Nietzsche;cf. ainda Mann, Thomas, Betrachtungen eines unpolitischen;Simmel, G., Der Begriff und die Tragödie der Kultur; Cassirer,Philosophie der symbolischen Formen, entre outros.

${ }^{18}$ Neste sentido, Benjamin se refere à Liga Spartakista e a Blanqui, nas teses "Sobre o Conceito de História" e nas Passagens. .
} 
tê-lo regrado sob um modo de funcionamento uniforme"19 O que, sabe-se, Descartes consegue pelo domínio da natureza exterior ao homem pela mecânica, domínio da natureza no interior do homem pela medicina e pela moral.

Contrariando o otimismo cartesiano e seu ideal da evidência racional, bem como a óptica e a dióptrica que pretendem expulsar os fantasmas da visão, o barroco entende o mundo como uma "utopia ao revés", paródia da "realidade", pois esta é sono e sonho. Como podemos ler no Drama Barroco, Gryphius, entre os alemães, foi quem mais valorizou tudo o que diz respeito a espíritos, fantasmas e sonhos proféticos ${ }^{20}$. Porque fábula ou teatro são o mundo e a procura da verdade ${ }^{21}$. A realidade assim transfigurada se encena no "gran teatro del mundo", teatro de ilusões no qual nunca poderemos estar seguramente de posse da verdade, já que apenas nos é dado mudar a maneira de errar. No universo em que todas as verdades podem se contradizer, não se está longe de afirmar que "a contradição é a verdade",22, pois, no barroco, todas as coisas caem no vazio, adágio que reavê temas do estoicismo e do materialismo antigo de Lucrécio que, no Da natureza das Coisas, nega a organização divina do cosmos, pois esse céu está povoado de divindades inúteis. Aqui a vida é " uma fábula contada por um tolo (idiot), cheia de ruídos e fúria, significando nada."

Se no plano do conhecimento o homem se perde na impermanência das aparências,no plano da ação é colhido na "roda da fortuna".O retorno da deusa do panteão antigo no barroco corresponde à nova economia mercantil européia,dos empreendimentos da concorrência econômica e a da ontologia do risco. Ao contrário da Idade Média e seu gosto pela estabilidade, que alertava contra a vanitas sobre a qual tinha poder a caprichosa deusa que manifestava a tendência de todas as coisas a tourner mal, a modernidade depreende da roda do destino uma metafísica da sorte, da ascensão e da queda, todos os riscos da vita activa na qual domina o acaso para os êxitos ou fracassos na vida. Fator de heteronomia e marca de impotência, a fortuna tem poder sobre a contingência que impera nos assuntos humanos. Assim, se a natureza está sujeita ao aleatório, o hábito e o caráter ainda mais, pois se o hábito leva à repetição, a simples constância não garante a necessidade de se fazer o que já

\footnotetext{
${ }^{19}$ Guenancia,Pierre, Descartes et l'ordre politique, PUF,1983, p. $26 .$.

${ }^{20}$ Cf. op. cit., p. 157.

21 Cf. Champiguy,R., "The Theatrical Aspect of Cogito",in Review of Metaphysics, 12,1959,pp 370-377.

${ }^{22}$ Cf. Merleau-Ponty escreveu apud Tenório da Motta,L. in Lições de Literatura

Francesa,ed. Imago,1998,p.59).
} 
se fez e fazê-lo sempre, o acaso podendo produzir ações incontinentes no homem virtuoso, e promover o injusto a prudente: "de que contrários consiste o homem! Que Impossível mistura! Vício e Virtude, corrupção e eternidade e, em um único homem, levam-no à perdição." ${ }^{, 3}$ Para metaforizar este estado, o barroco constrói cenas noturnas às quais Benjamin se refere no DB, associando caos e noite, como em Otelo:" chaos is come again". Em O Rei Lear, a tempestade é o caos, a natureza inteira, como uma vertigem do cosmos, gira ao redor da crueldade incompreensível da natureza e da natureza exterior e da humana. Em Macbeth o mundo noturno é o dos assassinos e feiticeiras e, segundo uma opinião generalizada à época, a meia-noite é a hora em que o tempo pára, como o ponteiro de uma balança: " o drama de destino", escreve Benjamin, " atribui importância dominante à hora dos espíritos[...]Como o destino, a verdadeira ordem do eterno retorno só pode ser concebida temporalmente num sentido figurado[uma vez que o tempo é repetição,é destino e fatalidade][...];suas manifestações[as do destino] procuram o tempo-espaço.Elas se imobilizam no meio da noite,janela do tempo em cuja moldura reaparece continuamente o mesmo vulto espectral." ${ }^{24}$

A modernidade é, para Benjamin, o retorno do destino e do domínio do acaso. O tempo da modernidade é espectral, sua atemporalidade é a do tempo paralisado, como o sol negro da acídia que estigmatizava uma " eternidade negativa", em um dia insuportavelmente longo. A hora barroca é a das aparições, porque "o medo dos espíritos não tem história" ${ }^{25}$.

A empatia - tanto a do positivismo quanto do historicismo - se realiza pelo determinismo dos fatos ou por seu essencialismo, empatia com o que há de obscuro e malogrado, identificação com os fantasmas do passado. Seus "mistérios" suscitam a curiosidade e o desejo de buscar em magos e adivinhos a contenção de angústias. Benjamin reconhece neste procedimento uma prática de imediação própria à Einfühlung em sua dogmática subtração do passado à experiência do presente. Ela é a idolatria do acontecido. A Einfühlung é, para Benjamin, "preguiça do coração", é acídia que evoca a idéia de curiosidade: "a empatia (Einfühlung) mascara a simples curiosidade com o disfarce do método[...]. Nessa aventura, a falta de autonomia característica da presente geração sucumbiu ao peso impressionante do Barroco, ao defrontar-se com ele" ${ }^{26} \mathrm{O}$ homem barroco não tem fé, só crenças substituíveis e inercambiáveis.

\footnotetext{
${ }^{23}$ Chapman,G., 1559-1634.

${ }^{24}$ Cf. DB, p 158.

25 idem,ibidem

${ }^{26} \mathrm{DB}, \mathrm{p}$ 76).
} 
No Drama Barroco, a acídia é o sentimento melancólico da onipotência da fatalidade que destitui de qualquer valor as ações humanas, conduzindo à submissão total à ordem existente, à consulta de astrólogos e árvores genealógicas que prosperaram na República de Weimar na época de ascensão do nazismo. Enquanto meditação profunda sobre a condição decaída do homem pelo pecado original que o reduz à condição de criatura, o Trauerspiel põe em cena a contingência de um mundo em que tudo se equivale, em que o homem é simples suporte (Träger) de constrangimentos e coerções; dominado por esta "lógica" que ele não domina, deixando-se atrair pelo cortejo solene e majestoso dos poderosos. Deste modo, pode-se dizer que a Primeira Guerra Mundial, como fantasmagoria, já assombra o homem antes de deflagrada, e se tornava cada vez mais inapelável e definitiva à medida de sua aproximação.

Inapelável é o curso da história que se desenrola no palco barroco, porque ele é a temporalidade da repetição: "É sobre a repetição que se baseia a lei do Trauerspiel[...]. [Este] esgota artisticamente a idéia histórica da repetição" 27 que , diferentemente da tragédia antiga não produz imortalidade, mas somente espectros e assombrações, porque " onde não há mais deuses, reinam os espectros".(Novalis). Nele se dissociam significante e significado, de tal forma que as ações e as coisas podem ter qualquer sentido ou sentido algum. De onde o conceito de história natural, a queda da história em natureza segundo a idéia de ciclo ou de repetição.

O pessimismo histórico do barroco alemão compreende que o homem é cego, sem vontade própria ou com vontade fraca: "a humanidade atual vacila, às cegas, em um labirinto cuja entrada, saída ou estrutura ninguém conhece. Eis o que chamamos a história" ${ }^{28} \mathrm{Se}$ a escatologia pensava em acelerar o tempo histórico para a chegada do Messias e para a redenção, o barroco não acredita no além, o fim dos tempos é a catástrofe que é preciso retardar e evitar a qualquer preço por meio da soberania inviolável do soberano ${ }^{29}$. No DB, Benjamin observa: "o soberano representa a história. Segura nas mãos o processo histórico como um cetro" ${ }^{30}$. Seu duplo moderno encontra-se na Ditadura de Schmitt, no qual Benjamin reconhece a história que se torna natureza, a modernidade aparecendo em sua facies hyppocratrica como "estado de exceção em permanência".

\footnotetext{
${ }^{27}$ Origine p 258)--

${ }^{28}$ Aqui Benjamin acompanha Donoso Cortez,apud Schmitt, Théologie politique, p-. 67.

${ }^{29} \mathrm{O}$ absolutismo monárquico foi preparado pelo assassinato de Henrqique IV na França durante as guerras de religião, quando os protestantes recusavam o poder da cúria e não permitiam destituir um príncipe considerado tirano. ${ }^{30}$ Origine, p 65.
} 
O estado de exceção se manifesta entre a política e o direito, em uma circunscrição incerta e paradoxal, pois, como no artigo 48 da Constituição de Weimar,apresenta-se como a forma legal do que não poderia ter qualquer legalidade. Dando continuidade à análise da exceção benjaminiana nos séculos XVII e XX, Agamben analisa a suspensão das liberdades individuais e direitos civis por Hitler no "Decreto para a proteção do povo e do Estado", de 28 de fevereiro de 1933, decreto vigente por doze anos no período do Terceiro Reich: :"o totalitarismo moderno pode ser definido, neste sentido, como a instauração, através do estado de exceção, de uma guerra civil legal, que permite a eliminação física não apenas dos adversários políticos, mas de categorias inteiras de cidadãos que, por uma ou outra razão, parecem não integrados ao sistema político. A partir de então, a criação voluntária de um estado de emergência permanente (mesmo não sendo declarado em seu sentido técnico) tornou-se uma das práticas essenciais dos Estados contemporâneos, inclusive daqueles denominados democráticos." ${ }^{31}$ Neste sentido, trata-se de uma indeterminação entre democracia e absolutismo. História-natureza significa que a natureza é o reino do inorgânico, retorno do vivo ao inerte, à condição de objeto ou coisa sem defesa.

Contra a hegemonia da história historicista e positivista e sua idolatria do símbolo e do fato consumado, de sua utopia do significado único dos acontecimentos, a alegoria barroca recupera seus desvios e deslocamentos. Neste sentido, Benjamin cita, nas Passagens, obras que recenseiam diversos períodos da história e a arquitetura dos arcos do Triunfo, da Roma Antiga a Napoleão III. Que se pense nas alegorias barrocas dos baixos-relevos dos arcos de triunfo em que, príncipes vitoriosos, no alto de triunfantes carruagens, arrastam atrás de si vencidos escravizados e baús transbordantes de ouro, jóias, cortejos triunfais, mas abalados na marcha por um instante de interrupção temporal, de iluminação. Contra chronos o kairós.

Na senda de Maquiavel, o Jetztzeit é a virtù , a tentativa de vencer a dramaticidade do desencontro entre o $\mathrm{Eu}$ e o Mundo, revelando uma experiência histórica em que dois momentos separados no tempo se relacionam e, sendo messiânico, reconcilia o passado e o presente, vencendo o que no passado esteve separado de si mesmo e se perdeu. Se os acontecimentos na história se apresentam em sua desunião, o Jetztzeit é união do que se desuniu, se perdeu e dispersou. Se a experiência histórica é quase sempre trauma e choque, interrupção da identidade e dissolução, o Jetztzeit é desalienação radical, é o verdadeiro " estado de exceção".

\footnotetext{
${ }^{31}$ Agamben, G. État d'exception, ed Seuil, Paris,2003,p.11.
} 
Nos Rastelli Raconte, Benjamin comenta Veneza e seu corso, durante o carnaval que " é um estado de exceção", derivado das antigas saturnais, quando o alto e o baixo trocam de lugar e os escravos se faziam servir por seus senhores. Ora, um estado de exceção só pode se definir em oposição total a um estado costumeiro", pois, aqui,terminada a festa tudo volta ao normal, o alto retomando seu lugar. No "verdadeiro estado de exceção" não há mais poderes autoritários - como o " estado de exceção" da ditadura schmittiana nem alto nem baixo. Será a sociedade sem classes e, de maneira mais fundamental, a da divisa: ni Dieu ni Maître. ${ }^{32}$

\footnotetext{
${ }^{32}$ Cf. Benjamin, tese n VIII de "Sobre o Conceito de História”, in Obras Escolhidas I, trad. Sérgio Paulo Rouanet, ed Brasiliense, 1983.; Benjamin e seu esnaio sobre Bachofen e o matriarcado, bem como a utopia do feminino como não dominação, como no fragemtno "Sócrates", em que Safo é personagem de Eros e Sócrates do logos. Rochlitz, R., Lê Désenchantement de l'Art,ed Gallimard, 1992;Löwy, M., Avertissement d'Incendie:une lecture des theses “ Sur le Concetp de l'Histoire”,ed Puf, paris,2001; cf. ainda a antologia do anarquismo, org. de Guérin,D. Ni Dei ni Maître, ed La Decouverte, Paris.
} 